\title{
LETTERS
}

\section{Is there a real increased risk of stroke in patients with dengue fever?}

We read the article on risk of stroke in patients with dengue fever with great interest. ${ }^{1} \mathrm{Li}$ and colleagues concluded, "In this population-based study, the presence of dengue was associated with an increased risk of stroke. The effect of dengue on stroke may be acute rather than chronic." 1

We would like to share ideas and experience from our country in Indochina, where there is an extremely high prevalence of dengue. Neurologic complication from dengue is possible, but stroke is extremely uncommon. ${ }^{2}$ It is unlikely that the present study adequately controlled for the other confounding factors that might result in the occurrence of stroke. If there is an actual increased risk, there should be a plausible pathomechanism. In fact, the main problem in dengue is hemostatic disorder, and the only possible mechanism is hemorrhage. Nevertheless, hemorrhagic stroke is rare, and good clinical supportive care for acute dengue infection is usually sufficient to prevent complications. ${ }^{3}$

\section{Beuy Joob PhD}

Medical professor, Medical Academic

Center, Bangkok, Thailand

Viroj Wiwanitkit MD

Medical professor, honorary professor, Dr. D.Y. Patil University, Pune, India

Cite as: CMAJ 2018 August 7;190:E940. doi: $10.1503 / \mathrm{cmaj} .69471$

\section{References}

1. Li HM, Huang YK, Su YC, et al. Risk of stroke in patients with dengue fever: a population-based cohort study. CMAJ 2018;190:E285-90.

2. Wiwanitkit S, Wiwanitkit V. Neurological complications in dengue infection. Arq Neuropsiquiatr 2014;72:259.

3. Wiwanitkit V. Intracranial hemorrhage in dengue: Where is it? Asian J Neurosurg 2017;12:804.

Competing interests: None declared. 